\title{
Basava Philosophy and its Relevance to Management - a Study
}

\author{
M. Nirmala' and N. E. Pradeep ${ }^{2 *}$ \\ ${ }^{1}$ Assistant Professor, Canara Bank School of Management Studies, Bangalore University, Bangalore, India \\ ${ }^{2}$ Research Scholar, Canara Bank School of Management Studies, Bangalore University, Bangalore, India
}

\section{Abstract}

Contemporary management is a multidisciplinary function, which is harmonized and integrated mutually, with varied disciplines. Aside organizations are open to learn from the historical evidences and experiences to enhance their performance in overall, also global organizations are making an effort to move on from ethnocentric cultural perspectives towards common cultures. In this regard, Basava Philosophy can contribute immensely towards efficient management practices, and this study is an attempt to establish the management perspectives from Basava Philosophy.

Keywords: Basava Philosophy, Work Culture, CSR, Kayaka, Dasoha

\section{Introduction}

Basava philosophy is the universal work of Sri Basaveshwara (also known as Basavanna and Basava) which emphasised on 'Kaayaka' (meaning work) and 'Dasoha' (meaning service by sharing) [Brown (2003), Gajendragadakar (1967) and J P Shouten, (2003)]. Basavanna's thoughts had created the spark among the people and society during 12th century and he had set up a colloquium by name 'Anubhava Mantapa', where the people from all class and levels had a chance to speak on their real life situations which was allowed for open discussion and the same was recorded in the literature form referred to as 'Vachanas'. The greatest contribution of the Anubhava Mantapa was not just discussing but it engaged people to practice the preaching in real life. This reveals an idea that Basavanna was a great thinker and visionary; by experience he had generated a great sense to uphold the human values and rights.
Management is an art of getting things done by others. Management is the process of designing and maintaining an environment in which individuals, working together in groups, efficiently accomplish selected aims. Management has been understood as a function of planning, organizing, staffing, leading and controlling. The concept of management has been evolved and developed since ages and been elaborated in brief by schools of management thoughts. There have been tremendous contributions by researchers and practitioners to the concept of management; as a result management has been understood in different thoughts. In management, managers have multiple roles to perform and in the order they are influenced by not just internal environment but also affected by the external environment. The constraining influences of external factors on the enterprise are even more crucial in international management and these external factors may be economic, ethical, political, legal, ecological, social

*Email: pradeep.ne@gmail.com 
and technological. Management as a function has its roots deeper in the society.

The role of managing human skills is critically important to keep the organization connected across businesses and with the society where it exists. In this context, we need to understand the motivational factors of human resources, human values and ethics and also the importance of society influencing human resources. If we could relate to Maslow's theory of needs where 'Selfactualization' is the final level in hierarchy, and it refers to the stage where an individual is satisfied and would not be motivated anything after this level. Similarly the concept of 'Corporate Social Responsibility' is a phenomenal approach of management to compliment its compassion for the society where the organization exists. At every stage of management, human values and ethics need to be respected as the same replicates in the aspects of organization culture. On realizing such facts it is essential to understand the correlation of Basava philosophy and management in order to achieve the development of human resources.

Basava philosophy advocates a new dimension to management in developing the human resources. There has been studies conducted on Basava philosophy which unveil the key concepts in the philosophy i.e. about 'Kaayaka' (work) and 'Dasoha' (Sharing) which may be related to the contemporary management. Also there has been detail on 'Anubhava Mantapa', a forum setup by Basavanna which was open for all castes, for all men, for all seekers of knowledge, truth and God (Palekar, 2002). This forum represents today's conference rooms in the corporate world where the discussions and transfer of knowledge happens for an objective in course. Basavanna emphasizes on compassion for all to attain equality through self-realization. Adherence to the moral law within, ensures true progress of man not only from savagery to civilization, but also from man as subject to man as sovereign (Srinivasan, 1996). Basaveshwara has contributed immensely towards the well-being of society and overall development of human relations. In today's world every individual mostly build their desires for materialistic well-being however ignore every other aspects of societal needs. This desiring behavior is though not a new phenomenon as such, it has been present since ages. In early period, individuals practiced occupation which was mostly hereditary in nature and were able to satisfy their needs by exchanging their produced goods and services with goods and services they required. However in contemporary scenario hereditary occupations have been replaced by organizational structures and entrepreneurial enterprises. This process has enabled individuals to learn and practice occupations of their choice, thus while performing the duties each individual would remain the asset of such organization which has hired them. Is every individual in the society considered for employment? On employment, do every individual earn same income? Is profit the right of owner or is it equally distributed among employees? Do women have equal opportunity to work? Do employees follow organizational ethos? Many such questions have been unanswered appropriately. In the course of understanding the management lessons from Basava Philosophy, it would be appropriate to find the principles in Basava Philosophy which could be of relevance to Human Resource Management. Basava philosophy as a model based on egalitarian approach it brings out the essence of work culture, work place ethos, social responsibility among individuals, equality, commitment and dignity of labour, which among them includes:

Kaayaka (Work) - Adoctrine which explains the dignity of labor, that there is no difference in the kind of work one performs but every work is equal and therefore one-self should perform it with total dedication and divinity. Basava expressed through this philosophy about the importance of work as "Kayakave Kailasa", where he denote that 'Work is Divine'. The philosophy also preaches that one has to work just not to earn a living for self rather should the means of work should be ethical in nature. Kaayaka not just emphasizes 'Dignity of Labour' but it encourages 'Divinity of Labour'

Dasoha (Sharing) - This principle emphasizes that the earning which is in excess than required to satisfy the physiological needs of individual should be shared through distribution to the wellness of society. By this amassing of wealth will not be an aspect of the society otherwise every member of the society will serve to care for each other's voluntarily. 
Basava Philosophy has lucid approach towards guiding individuals in their day to day activities in the way of practicing righteousness, responsibility and ethical standards at the workplace. Aside Basava Philosophy could be relevant to various functions of management performed by individuals in the organization.

\section{Review of Literature}

At the time when Basavanna appeared on the scene, the conditions were even worse than they were, at the time when Buddha was born. Society was in the strong hold of casteism and suffered by the intrusion into it of blind belief and superstition. The vast majority of the people were sunk in ignorance; and in human practices like untouchability were weakening the social structure. In the hour of such a crucial need Basava took up virasaiva religion and made it a vehicle to proclaim his universal message of a religion of humanity (Thipperudraswamy, 2012). Thus, Thipperudraswamy has compared the aspects of Virasaivism and Buddhism philosophy in a subtle manner under religious view. In this aspect he states that every religion must have more or less a philosophical basis which usually includes five fields of study namely - Logic, Aesthetics, Ethics, Politics and Metaphysics.

Ramjan Darga in his paper "Jaativyavastege Savalaada Sharanaru", details on the social orientation of Sharanas, who lived during 12th century. Sharanas followed secular approach and they were free from caste based and other social inequalities. They all thrived to attain the objectives of sharana philosophy by creating an egalitarian society where all people enjoy equal status in terms of social equality and economic equality through the phenomenal principles of Kayaka and Dasoha (Darga, 2013).

Schouten highlights four aspects of the progressive social teaching of the Lingayat Movement. Most remarkable is the radical rejection of caste distinctions, which lies behind each of his other three emphases. His second point is the dignity of labor in the Lingayat movement; here occupations are not hierarchically ranked, and none are considered unclean. Thirdly, Schoten highlights the elevation of women in Lingayatism. Finally, education and learning are stressed for all peoples rather than being the preserve of the high castes (Schouten, 1995).

Munshi, a political and religio-cultural leader and founder of the Bharatiya Vidya Bhavan, has stated "Sri Basaveshvara, the great saint, poet and philosopher of Karnataka, occupies a very prominent place among the mystics and religious reformers of Bharata (India). He was born at a time when society driven by political upheavals, social schisms and religious animosities. He preached the message of universal love and brotherhood, righteous conduct and devotion to God and spread the doctrine of social equality". Compassion reaffirms, reflects, resonates and reverbates the Veershaiva Philosophy of Kayaka and Dasoha (Munavalli, 2007). Overall Dr. Munavalli brings out the key terminologies of veerashaiva religion and attempts to explain the concepts of religious relevance.

According to Shivamurthy Shivacharya Swamiji, emancipation of women or the spiritual equality is another "important dimension in the humanitarian aspects of Shivasharana". Basaveshwara and other Shivasharanas have made untiring efforts by putting all their energy for building a society of equals where both men and women could participate in spiritual and religious spheres on equal footing. Discrimination or exploitation of women on the basis of sex is against the very principle of rationalism of Shivasharanas, the religious movement of Basaveshwar and other Shivasharanas at Kalyan against the discrimination of caste, creed or sex attracted people across the country including women. According to Veerashaiva Philosophy of which Basaveshwar was the champion, men and women differ only in physiological level but they are one and the same in metaphysical effect. (Shivamurthy, 1985).

Geetha and Palekar states that Anubhava Mantapa was one of the democratic structure, in which both men and women were participating in discussions and deliberations. Their ideas were expressed through their Vachanas (literary poems). Their ideas expressed revealed that women are also equal or even greater to men. Hence the principles and philosophy of Shivasharanas on 
emancipation of women is much to be appreciated and such ideas are relevant for the present society (Nagesh \& Palekar, 2012).

Basaveshwara spoke in terms of social equality, caste and class equality, occupational equality, religious equality, equality of sex and so on which act as a catalyst for social change. Basaveshwara's 'Kayaka' theory insists on the honest discharge of occupational responsibilities (Jadhav, 2014).

P.B. Gajendragadakar, former Chief Justice of Supreme Court of India, states that Basava deserves a place a pride in this galaxy of great dissenters and redeemers. In his writings he emphasizes on the work of Basaveshwara in the arena of socio-religious perspectives and upholds that religion which Basava preached, was essentially a social religion. Justice Gajendragadakar includes that the creed of Basava is a permanent revolution against the power of priesthood, against dogmatism, templecults, caste and class privileges and social inequality in every form (Chief Justice P.B.Gajendragadkar, 1967).

Dr. Johan Petes Shouten in his essay 'Revolution of Mystics - social aspects of Veerashaivism' outlays the social aspects of Virasaivism which elaborate upon the origin of the virasaiva movement, religious teachings and customes prevailed in virasaiva culture and evaluates on these aspects. Thus, Shouten upholds every practice of the cult and states that the heritage of Basava and his contemporaries is obviously a living tradition which is capable of inspiring a community ever after eight centuries. Mr. Shouten is excited to understand the humanitarian outlook, compassion towards living beings, equality among men and women, courageous efforts to eliminate the clutches of castes and creeds, the way in which religion was made the way of life found in his study and at the same time he fees sorry for the present day situation even among the followers of Basavanna. The writer firmly says that the religion evolved by Basavanna was the real religion of humanity (Shouten, 2003).

Patil in his doctoral work "Contribution of Basaveshwar to Indian Jurisprudence", has noted on concepts in which Basaveshwara emphasize upon i.e. equality, equity, work, untouchability, emancipation of women and socialistic idealism. The researcher has attempted to comparatively analyze the works of Basaveshwara with eminent social reformers and thinkers. This research has been able to elaborate on the importance and relevance of Basaveshwara's preaching's to various disciplines and times (Patil, 1996).

The review of literature pertaining to Basava philosophy has been multi-dimensional learning, which deliberates on the grounds of Social, religio-spiritual, ethical, economical, scientific arena and in the space of literature. In the study it is learned that Basava Philosophy is a universal phenomenon and can be applicable across space and times. In this regard, the researcher has observed that the study on the relevance of Basava Philosophy in the domain of Business Management and Human Resources Management is partial, in this context researcher progress to examine the relevance of Basava Philosophy to contemporary management functions.

\section{Research Analysis}

\subsection{Hypothesis 1}

$\mathrm{H}_{0}$ : The principles of Basava Philosophy are of no significant relevance.

$\mathrm{H} 1_{1}$ : The principles of Basava Philosophy are identified and have significant relevance.

Table 1. Key principles of basava philosophy

\begin{tabular}{|c|c|}
\hline Principles & Key Principles of Basava Philosophy \\
\hline Kayaka & 32 \\
\hline Dasoha & 18 \\
\hline Equality & 15 \\
\hline Jangama & 10 \\
\hline Humanity & 8 \\
\hline Bhakti & 7 \\
\hline
\end{tabular}




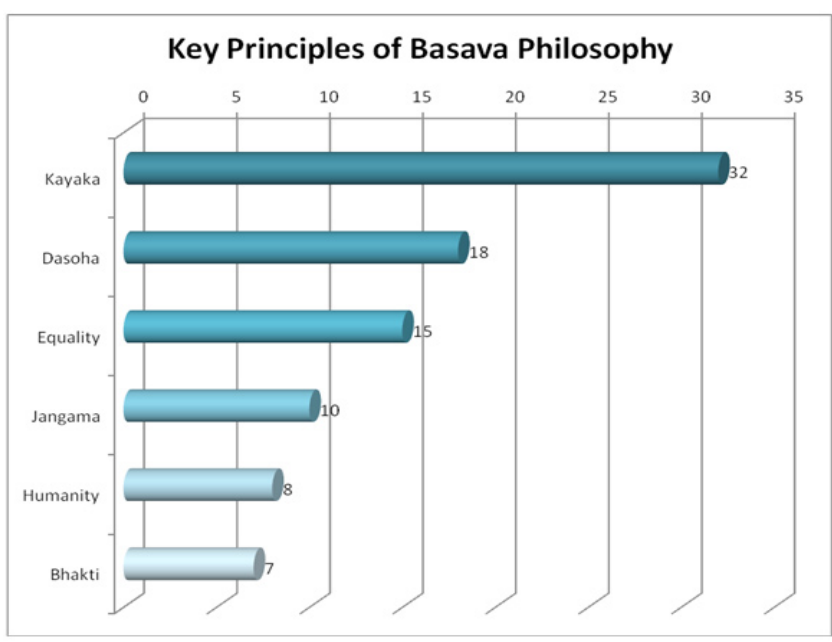

Figure 1. Key principles of basava philosophy.

Table 2. Application of basava philosophy to business environment

\begin{tabular}{|c|c|}
\hline Business Areas & Applicable to Business environment \\
\hline Work Culture & 24 \\
\hline Ethical Practices & 17 \\
\hline Economic responsibility & 10 \\
\hline Social responsibility & 9 \\
\hline Communication & 6 \\
\hline Leadership & 3 \\
\hline Spiritual approach & 3 \\
\hline Emotions & 3 \\
\hline Customer Relations & 1 \\
\hline
\end{tabular}

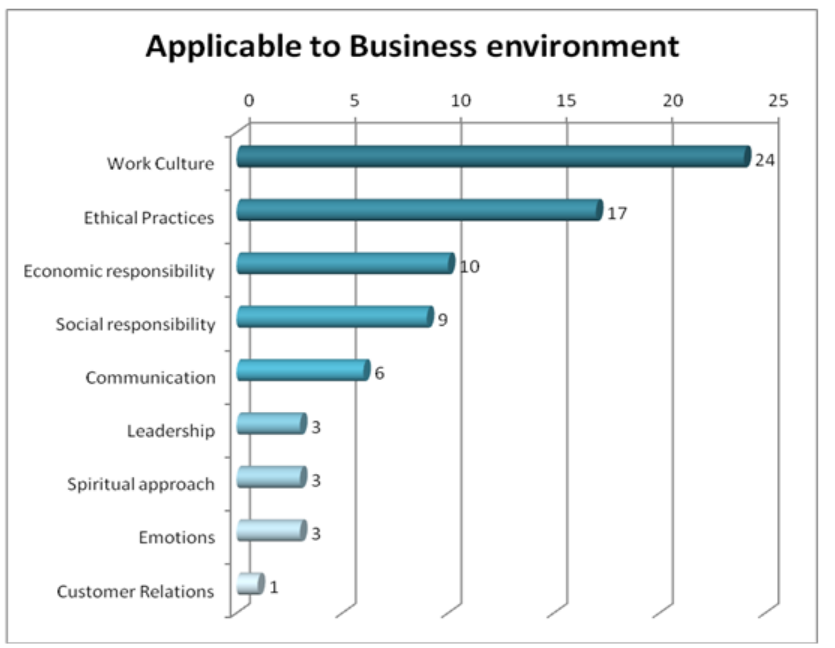

Figure 2. Applicable to business environment.
Table 3. Application of basava philosophy to human resources

\begin{tabular}{|c|c|}
\hline HR_areas & Applicability in Human Resources \\
\hline Work Culture & 30 \\
\hline Equality & 13 \\
\hline Social Responsibility & 11 \\
\hline HR Ethics & 7 \\
\hline Attitude & 6 \\
\hline Motivation & 6 \\
\hline Leadership & 6 \\
\hline Personality development & 6 \\
\hline Economic Responsibility & 5 \\
\hline Communication & 4 \\
\hline Spiritual aspects & 4 \\
\hline Governance & 3 \\
\hline Decision making & 3 \\
\hline Diversity Management & 3 \\
\hline Humanity & 2 \\
\hline Training & 2 \\
\hline Rewards & 2 \\
\hline Time Management & 1 \\
\hline
\end{tabular}

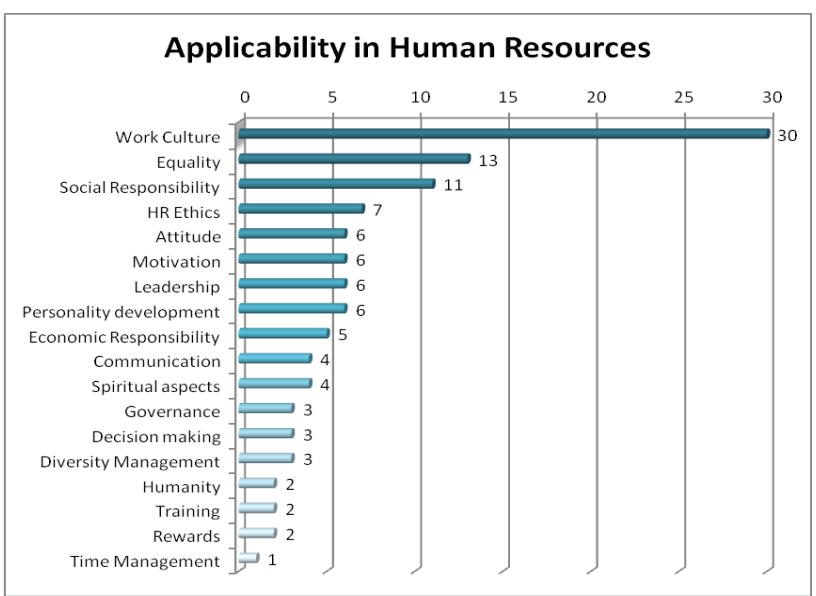

Figure 3. Applicability in human resource

\subsection{Hypothesis 2}

$\mathrm{H} 2_{0}$ : There is no significant scope for Human Resource function to identify and implement the best practices from Basava Philosophy.

$\mathrm{H} 2_{1}$ : There is significant scope for Human Resource function to identify and implement the best practices from Basava Philosophy. 


\subsubsection{Test}
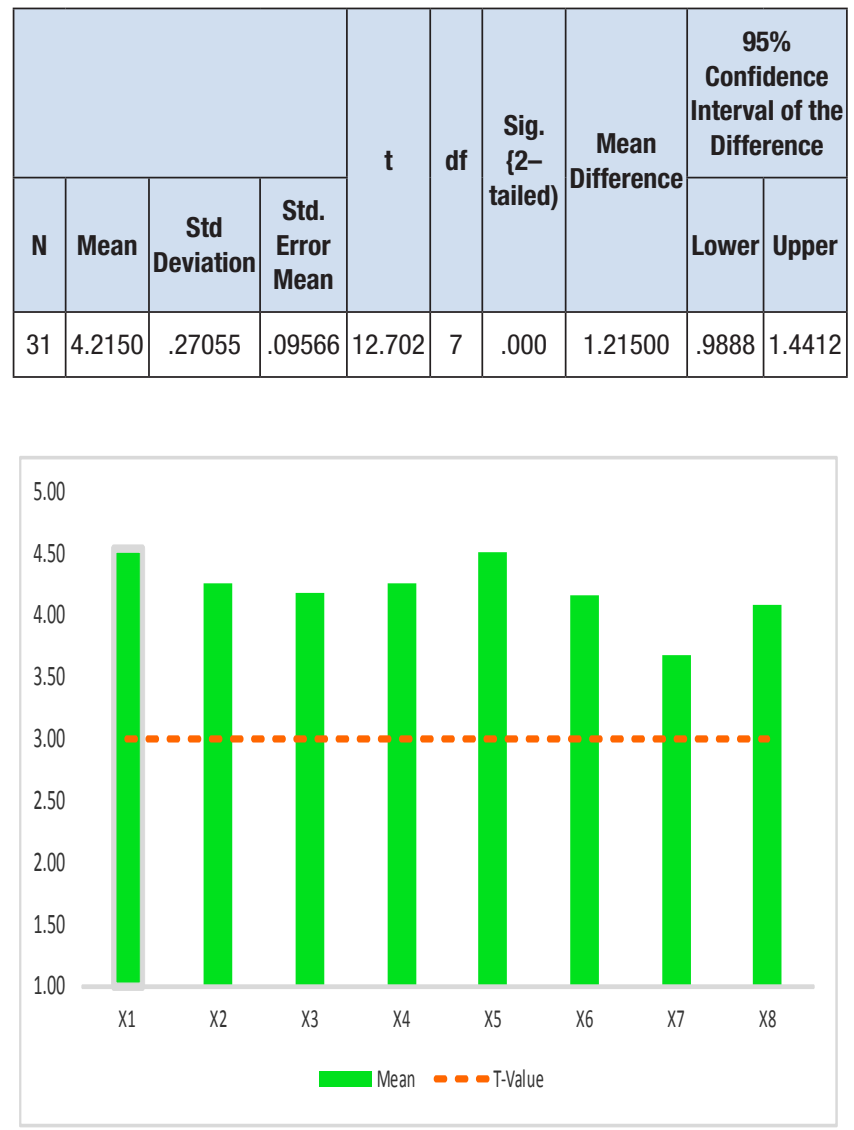

\subsubsection{Interpretation}

The above respondents achieved the mean score of 4.2150. The t-value is 12.702 and it is statistically significant at 5\% level. Hence null hypothesis is rejected and alternate hypothesis is accepted. It is inferred that there is significant scope for Human Resource function to identify and implement the best practices from Basava Philosophy.

\subsection{Hypothesis 3}

H3: Basava Philosophy doesn't enables human resources to develop their social, economic and cultural responsiveness.

$\mathrm{H}_{1}$ : Basava Philosophy enables human resources to develop their social, economic and cultural responsiveness.

\subsubsection{Test}
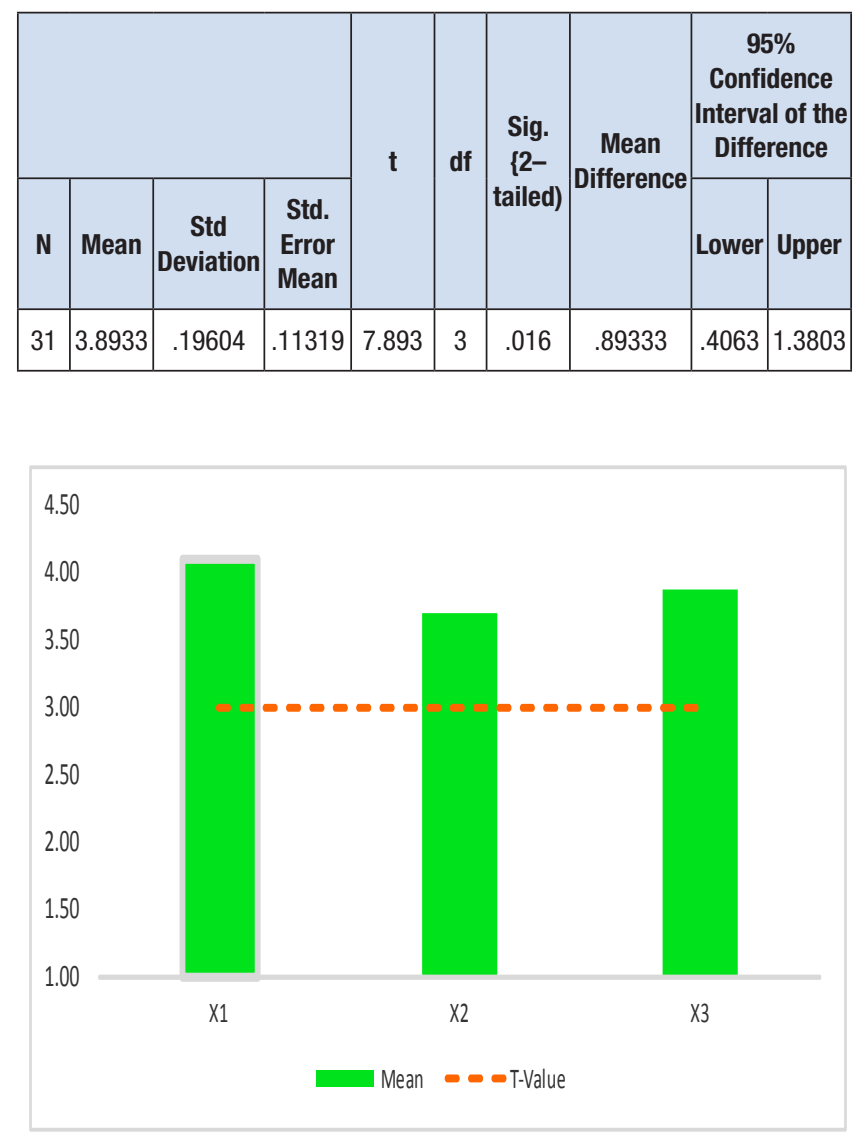

\subsubsection{Interpretation}

The above respondents achieved the mean score of 3.8933. The t-value is 7.893 and it is statistically significant at 5\% level. Hence null hypothesis is rejected and alternate hypothesis is accepted. It is inferred that there is significant scope for Human Resource to develop their social, economic and cultural responsiveness.

\subsection{Hypothesis 4}

$\mathrm{H}_{0}$ : Basava Philosophy cannot be implied in organizational management practices and applied in Human Resource function.

$\mathrm{H} 4$ : Basava Philosophy can be implied in organizational management practices and applied in Human Resource function. 


\subsubsection{Test}

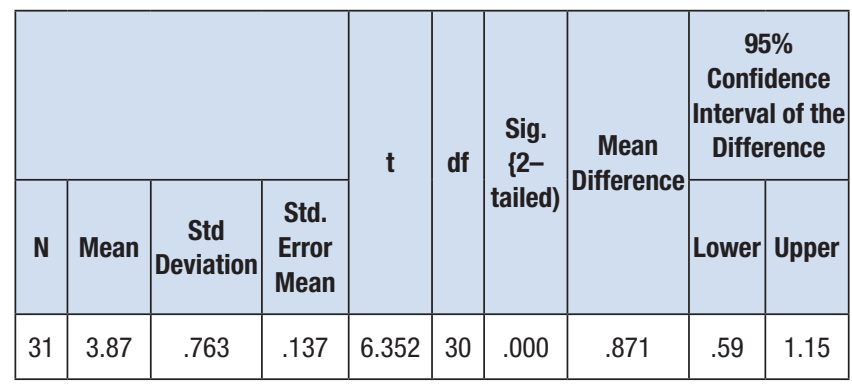

\subsubsection{Interpretation}

The above respondents achieved the mean score of 3.87. The t-value is 6.352 and it is statistically significant at 5\% level. Hence null hypothesis is rejected and alternate hypothesis is accepted. It is inferred that Basava Philosophy can be implied in organizational management practices and applied in Human Resource function.

\section{Key Findings}

In the study, researcher has established the following findings:

- Key principles of Basava Philosophy includes Kayaka, Dasoha, Equality, Jangama, Humanity \& Bhakti

- Identified principles are relevant to contemporary management practices

- Basava Philosophy can support management in the development of work culture, work ethos, socio-economic responsibility and human values

- Human Resource function has several take away aspects from Basava Philosophy

- There is scope of engaging Basava Philosophy in the function of CSR.

\section{Outcome of the Study}

On review of findings from the study, it is to summarize that Basava Philosophy will be of great importance to contemporary management functions which among employees it develops:
- Economic Responsiveness

- Social Responsiveness

- Cultural Responsiveness

Basava philosophy, as a model based on egalitarian approach, it brings out the essence of equality, commitment, consistency and dignity of labour. The key principles of Basava Philosophy include:

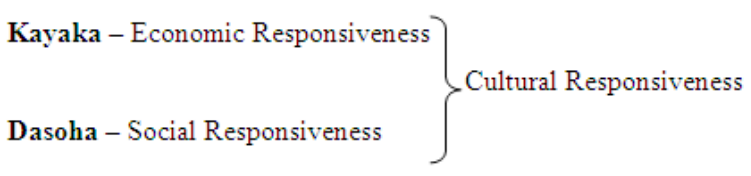

\subsection{Kayaka (Work)}

A doctrine which explains the dignity of labor, that there is no difference in the kind of work one performs but every work is equal and therefore one-self should perform it with total dedication and divinity. Basava expressed through this philosophy about the importance of work as "Kayakave Kailasa", where he denote that 'Work is Divine'. The philosophy also preaches that one has to work just not to earn a living for self rather should the means of work should be ethical in nature. Kaayaka not just emphasizes 'Dignity of Labour' but it encourages 'Divinity of Labour'.

\subsection{Dasoha (Sharing)}

This principle emphasizes that the earning which is in excess than required to satisfy the physiological needs of individual should be shared through distribution to the wellness of society. By this amassing of wealth will not be an aspect of the society otherwise every member of the society will serve to care for each other's voluntarily.

The above principles indicate the scope of philosophy to extend its relevance in managing human resources by creating strong emphasis in:

- Engaging in Social Responsibility

- Work they perform

- Stakeholder's relations

- Aligning and achieving organization's goal

- Adapting and contributing to society they exist

- Work ethos 


\section{Conclusion}

Thus, to conclude Basava Philosophy is a universal work which can be of relevance to any and every discipline which exist and is related to society. In this regard Basava Philosophy can be an efficient source of relevance for management to achieve its organizational goals by effective management of its human resources.

\section{Bibliography}

Aadi, S. N. (2013, August). Vishwa samaanateya modala harikara - Basavanna. Basava Patha (pp. 14-19).

Ahamed, H. (2013, September). Annadolagondagalannu... (Adalitashahi mattu Basavanna). Basava Patha (pp. 23-28).

Akkuramutt, S.(2007,May).Kayaka-Dasohatatvagalalliruva naithika moulyagalu. Basava Patha (pp. 115-122).

Anuradha, B. M. (2014, September). Naithikathe: AndhuIndhu. Basava Patha (pp. 47-52).

Balekundri, V. (2007, December). Sharana samskruti: Jaagatikarana. Basava Patha (pp. 51-59).

Balekundri, V (2008, November). Vishwa aarogyakke sharanara sandesha. Basava Patha (pp. 9-16).

Baligar, S. S (2008, July). Arthasastra mattu basavaadi sharanara vicharagalu. Basava Patha (pp. 72-75).

Baligar, S. S (2012, January). Swavalambi badukige basavapatha. Basava Patha (pp. 36-43).

Baligar, S. S (2014, June). Manava sampanmoola nirvahane mattu basavatatva. Basava Patha (pp. 52-62).

Boratti, V. (2012). The Discovery of Vachanas: Halakatti and the medieval kannada literature in colonial karnataka. Hampi: Prasaranga, Kannada University.

Brown, C. P. (2003). Essay on the creed, customs and literature of the Jangams. In R.H.Chandangoudar (Ed.), 12th Century revolution for equality and social justice (pp. 1-52). Bangalore: Jagajyoti Trust.

Chakravorty, M. (2010, January 26). Mysticism without bounds: Perception of space. Melintas (pp. 41-51).

Chilami, R. B. (2010, December). Samaanateya harikara basavanna. Basava Patha (pp. 65-72).

Chilami, R. B. (2013, July). Vachana sahitya: Jaagatika savaalugalu. Basava Patha (pp. 55-71).

Dande, D. (2007, December). Vyaktitva vikasanakke sharanara sandesha. Basava Patha (pp. 29-32).

Darga, R. (2007, January). Basavanna: Kaayaka mattu Dasoha. Basava Patha (pp. 45-68).
Darga, R. (2013, July). Jaativyavstege savalaada sharanarau. Basava Patha (pp. 14-51).

Gajendragadkar, P. B. (1967). Homage to Basava. In G. o. Karnataka, Sri Basaveshwara - Commemoration Volume (pp. 53-56). Bangalore: Government of Karnataka.

Gowda, D. J. (2013, September). Kuvempu drushtiyalli basavanna. Basava Patha (pp. 12-22).

Gunjal, S. R. (2003). "Basava" in the eyes of others western scholars. In R.H.Chandangoudar, 12 th Century revolution for equality and social justice (pp. 74-76). Bangalore: Jagajyoti Trust.

Gupta, G. B. (2000). Humanism: An Over-view. Global Religious Vision. (pp. 5-16).

Hoogara, B. (2009, June). Basavannanavara vachanagalalli vyaktitva vikasana. Basava Patha (pp. 50-54).

India, T. T. (1918, April 17). Basavanna. The Times of India. (pp. 1).

Ishwaran, K. (1983). Religion and Society among the Lingayats of South India. New Delhi: Vikas Publishing House.

Jadhav, S. K. (2014). Basaveshwara's thoughts on social equality and social justice. International Journal of Research, 1317-1321.

Jainakeri, J. (2008, November). Vachana sahityadalli manovikasa. Basava Patha (pp. 68-76).

Jayashree, A. M. (2009, May). Basavannanavaru mattu maanaveeya moulyagalu. Basava Patha (pp. 42-46).

Karaveerashettar, S. G. (2008, May). Basavannanavara samvahana koushalya. Basava Patha (pp. 73-77).

Mahaswamiji, S. S. (n.d.). Sharana patha. Karnataka, India: JSS Publications.

Modi, K. (2014). Status of women in India. Online International Interdisciplinary Research Journal, 420424.

Munavalli, S. (2007). Lingayat dharma (Veerashaiva religion). Chicago: Veerashaiva Samaja of North America.

Mutt, S. D. (2014, June). Basaveshwarara tatvopadeshagalu: Prasthutha Saamajika samasyegalu. Basava Patha (pp. 71-77).

Nadkarni, M. V. (1992). Can There be an Indian way to development. Identifying the elements of Development Thinking in India (pp. 1-28).

Nagesh, G., \& Palekar, S. A. (2012). Role of shivasharanas in emancipation of women. Research Link (An International Journal), 67-69.

Palekar, S. A. (2002). Basaveshwara and human rights. Jaipur: ABD Publishers. 
Pande, D. (2000). The Bhakti movement - A Historiographical critique. Journal of Historical Research, 49-60.

Patil, J. S. (1996). Contribution of basaveshwar to Indian Jurisprudence - An Analysis. Rajkot: Saurashtra University.

Patil, K. (2014, September). Aadarsha rajakaarini Shri Basavannanavaru. Basava Patha (pp. 59-68).

Pavate, C (2010, May). Ivanarava ivanarava ivanaravanendanisadirayya. Basava Patha (pp. 58-63).

Pavate, S. (2008, June). Basavannanavaru mattu ekadevatavaada. Basava Patha (pp. 19-23).

Rachappa, R. (2008, November). Sharana samskruti. Basava Patha (pp. 34-44).

Rajanikant, A. R. (2010, November). Basavannanavara Kaanke-Kaanikegalu. Basava Patha (pp. 34-41).

Raju, L. (2013). Philosophy and Practice OF Virasaivas. Plainview,NY: Veerashaiva Samaja of North America.

Ramanujan, A. K. (1973). Speaking of Siva. London: Penguin Books.

Richard, H. L. (2007). Religious movements in hindu social contexts: A study of paradigms for contextual "Church" development. International Journa of Frotier Missiology, 139-145.

Sabarada, D. (2008, November). Basavannanavara vachanagalalli manovignana. Basava Patha (pp. 17-29).

Santosh, P. (2009, April). Bhavashuddha kaayaka. Basava Patha (pp. 56-60).

Schouten, J. P. (1995). Revolution of the mystics: On the social aspects of virasaivism. Delhi: Motilal Banarsidass.

Shankar, P. S. (2007, August). Vachana sahityadalli vaygnanika drushtikona. Basava Patha (pp. 14-30).

Shankar, P. S. (2007, December). Vyaktitva vikasanakke daarideepa. Basava Patha (pp. 33-39).

Shivamurthy, S. (1985). Veerashaiva view of men and women manifestation to God. Sirigere: Jagadguru Brihanmuth.

Shouten, J. P. (2003). Revolution of mystics. In R.H.Chandangoudar (Ed.), 12th Century revolution for Equality and Social Justice (pp. 57-73). Bangalore: Jagajyoti Trust.

Siddalingaiah, G. S. (2008, May). Kaayaka jeevigalu mattu basavanna. Basava Patha (pp. 9-14).

Siddhartha. (2008). Open-Source hinduism. Religion and the Arts 12 (pp. 34-41).

Sindagi,V.C.(2012).Vachanasaahityadallimaanavatavaada. Belgaum: Karnataka University.

Sindhura, S. (2009, February). Sharanara drushtiyalli kaayaktatva. Basava Patha (pp. 47-54).

Sudha, K. (2007, December). Vachanakaararu mattu vyaktitva vikasana. Basava Patha (pp. 44-50).
Thipperudraswamy, H. (2012, June 1). Virashaivism and Buddhism. Sharana Patha (pp. 35-47).

Tumakurakara, G. (2010, December). Jaagatikarana sandarbhadalli shivasharanara sandeshagalu. Basava Patha (pp. 31-36).

Ushadevi, C. G. (2010, February). Vachana sahitya mattu mahila sabalikarana. Basava Patha (pp. 26-30).

Veeraghantimutt, M. S. (2014, May). adhunika sandarbhadhalli basavannana vicharagala prasthutate. Basava Patha (pp. 41-51).

Waghmare, N.(2007). A StudyofRelevance of Basaveshwara's Vacana Shastra (Teachings) Across Time. Pune: Tilak Maharastra University.

Yatheeshwar C. H. (2008, August). Sharana sahitya mattu bharatiya samvidhana. Basava Patha (pp. 56-73).

Zvelbelil, K. V. (1984). The Lord of the meeting rivers: devotional poems of basavanna. UNESCO Collection of Representative Works, India Series (p. 118). Delhi: Motilal Banarsidass.

\section{About the Author}

Dr. Nirmala M. is working as an Assistant Professor having more than 19 years of experience in teaching and research. Author of Research methodology text book. More than 15 Articles are published in various National and international journals and participated and presented more than 30 research papers at National and International conferences and also chaired technical sessions at National and international conferences. She is guiding good number of research students and got an UGC Major Research Project on "Reaching the unreached through RTI". And also she initiated training program to SHG women's for implementation of their project and guiding them fund employment. Organised Faculty Development Program for eleven days to management faculty on Human Resource in collaboration with NHRD Bangalore chapter.

Mr. Pradeep N. E. is a Research Scholar in the faculty of Management Studies, Bangalore University. He holds Masters in Business Administration from Bangalore University, Post Graduate Diploma in HRM from KSOU and currently pursuing his $\mathrm{PhD}$ on the title "Basava Philosophy and its relevance to Management - A Study (with special reference to Human Resources)". He is a seasoned HR Professional 
and has 16 years of experience in Retail, ITES, He volunteers for various social initiatives, an FMCG, Entertainment and Academia. His expertise active member of National HRD Network, L \& is in areas of HR Technology \& Operations, Cross D Global and Karnataka HR Association. He also Cultural Communication and Employee Engagement. mentors budding entrepreneurs; provide consulting He has published research articles in various interna- services and training services to corporate houses tional and national journals and presented 24 research and academic institutions. He can be contacted at papers in international and national conferences. pradeep.ne@gmail.com. 